\section{Polio kursiert wieder in Europa}

Seit 2002 gilt Europa als polio-frei. Jetzt ist die Kinderlähmung wieder aufgetaucht. Die WHO hat zwei Fälle in der Ukraine bestätigt. Zwei kleine Kinder seien erkrankt. 2014 war nur die Hälfte der Kinder in der Ukraine gegen Polio geimpft. „Das ist ein Rückschlag", sagt Oliver Rosenbauer, Sprecher des Polio-Bekämpfungszentrums der WHO. Allerdings stünden die Chancen gut, den Ausbruch einzudämmen. „Das Virus ist nicht so aggressiv. Jetzt kommt es auf eine schnelle und umfassende Impfaktion an.

dpa/www.aerztezeitung.de

\section{Raucher entlasten die Gesellschaft}

Raucher in Deutschland entlasten Steuerzahler um hohe Milliardenbeträge. Denn: Raucher sterben ca. fünf Jahre früher als Nichtraucher und beziehen entsprechend weniger Renten. Dieser Effekt sei finanziell weitaus stärker als die Mehrkosten durch medizinische Behandlung oder frühzeitiges Ausscheiden aus dem Erwerbsleben, so eine Studie des Karlsruher Institut für Technologie (KIT). Hinzu kommen noch hohe Tabaksteuereinnahmen.

dpa/www.aerztezeitung.de

\section{Keimgefahr bei Muttermilchspenden}

Seit einiger Zeit kursieren Meldungen über Verunreinigungen und Panschereien bei Online-Angeboten von Muttermilch. Jeder zehnten Probe sei Kuhmilch beigemischt, so eine US-Studie. Experten weisen zudem auf die große Gefahr bakterieller oder viraler Verunreinigungen hin. Die Forderung: Milchspenden sollten den gleichen strengen Hygienevorschriften unterliegen wie Blutspenden. Die Experten raten zu industriell hergestellter Säuglingsmilch.

www.aerztezeitung.de

Ein halbes Mal mehr Sex?

\title{
Lustpille für die Frau: Zweifel an Wirkung
}

Geringe Wirksamkeit, deutliche Risiken - Kritiker werfen der US-Behörde FDA vor, sie habe sich bei der Zulassung der „Lustpille für die Frau“ von einer großen Kampagne steuern lassen.

„Even the Score“, so nennt sich der Feldzug von 26 US-Organisationen für die Gleichberechtigung in der Sexualmedizin. Grund: Es sind 26 Medikamente für Männer zugelassen, aber bis vor kurzem kein einziges für Frauen. Mit Flibanserin gibt es erstmals ein luststeigerndes Mittel für das weibliche Geschlecht. Eigentlich sollte es einer Zulassungsbehörde egal sein, ob irgendwelche Interessengruppen sich für oder gegen ein Medikament positionieren. Doch das dürfte nicht einfach sein, wenn ganz offen der Vorwurf des Sexismus in der Luft liegt.
„Die FDA hat eine Zulassung zweimal abgelehnt. Das einzige, was wir seit der letzten Ablehnung gelernt haben, ist, dass das Flibanserin noch mehr Nebenwirkungen hat, als angenommen“, so die Pharmakologin Prof. Dr. Adriane Fugh-Berman, Washington. Von der Wirkung sollten sich Frauen nicht zu viel versprechen. Nur 10\% der Frauen profitierten in Studien. Die Zahl der befriedigenden sexuellen Ereignisse unter Flibanserin $(100 \mathrm{mg} / \mathrm{d})$ stieg von etwa 3 auf 5 pro Monat, mit Placebo auf 4 bis 4,5. Das Mittel, dämpft die Freisetzung von Serotonin und erhöht die dopaminerge und noradrenerge Transmission. Grundlage für die Zulassung waren Daten von drei PhaseIII-Studien mit 2400 Frauen.
Wurst in Bärchen-Form, Comic-Figuren auf dem Joghurt - die Werbeindustrie gibt sich alle Mühe, Kinder für ihre Produkte zu gewinnen. Oft sind das aber Zucker- und Fettbomben. Experten fordern, der Werbung einen Riegel vorzuschieben.

Vertreter der Verbraucherorganisation Foodwatch, der Deutschen Diabetes Gesellschaft (DDG) und der Deutschen Diabetes-Hilfe „diabetesDE“ fordern schärfere gesetzliche Regelungen, um das Marketing für Kinderlebensmittel einzuschränken. Jene Produkte, die über Aufschriften, Gestaltungen oder Aktionen insbesondere Kinder ansprechen.

Auslöser ist eine aktuelle FoodwatchStudie, in der 281 Produkte getestet worden waren. Sie stammen allesamt von Her- stellern, die sich 2007 in der "EU Pledge“ $\mathrm{zu}$ einer freiwilligen Selbstbeschränkung beim Kindermarketing verpflichtet hatten.

\section{$90 \%$ zu süß und zu fett}

Der Test ergab, dass knapp 90\% davon nach Kriterien der Weltgesundheitsorganisation (WHO) zu süß und zu fett seien. Nur 29 Produkte hielten den WHO-Kriterien stand. Für die Verbändevertreter ist dies ein Zeichen, dass die Nährwertgrenzen im „EU Pledge“ $z u$ lasch und zugleich die Möglichkeit des Kindermarketing zu umfassend seien. „Marketing für Kinderlebensmittel muss per Gesetz eingedämmt werden, sonst werden Fehlernährung und Adipositas bei Kindern weiter zunehmen“, sagte DDGGeschäftsführer Dr. Dietrich Garlichs. (SW)

www.aerztezeitung.de 